\title{
A misdiagnosed abdominal tumor due to rare cause
}

\author{
Baoxing Jia, Yahui Liu \\ Department of Hepatobiliary and Pancreatic Surgery, the First Hospital of Jilin University, Changchun, China \\ Correspondence to: Yahui Liu, MD. The First Hospital of Jilin University, No. 71 Xinmin street, Changchun, China. \\ Email: liuyahuisci@163.com.
}

Submitted Feb 26, 2020. Accepted for publication Mar 26, 2020.

doi: $10.21037 /$ hbsn.2020.04.05

View this article at: http://dx.doi.org/10.21037/hbsn.2020.04.05

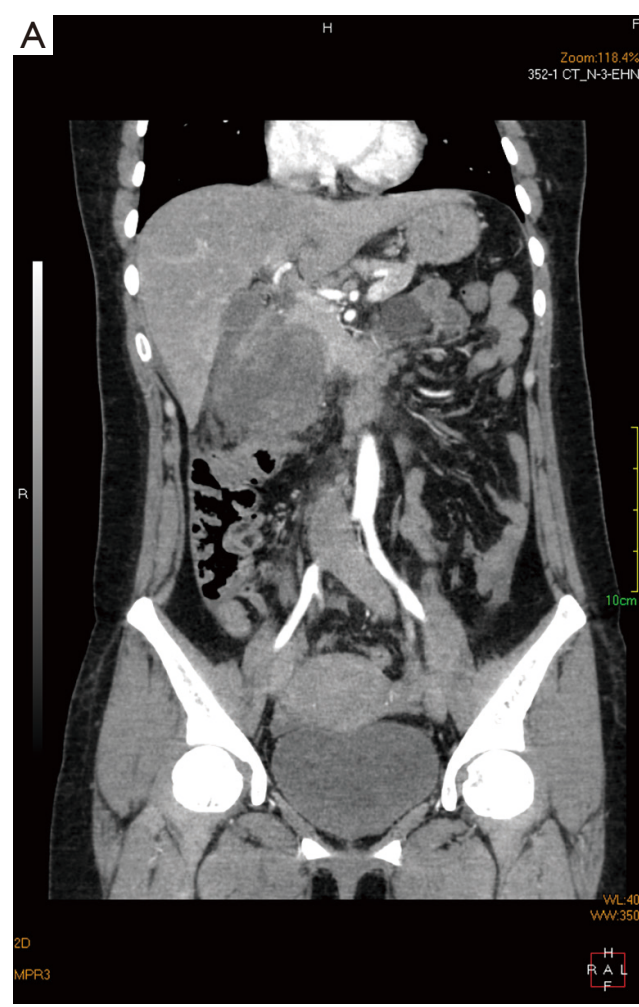

Due to 3-day dull pain in the right upper abdomen, a 41-year-old woman was admitted to the hospital. She had normal diet, bowel movement and no nausea or vomiting. Physical examination and laboratory tests were normal. Enhanced CT scan of the abdomen suggested a huge mass $(10 \mathrm{~cm}$ diameter) at the pancreatic head that infringed the duodenum and hepatic colon flexure; intratumoral bleeding was noted (Panel A). Three year ago, she had undergone a local chest wall resection for dermatofibrosarcoma protuberans (DFSP). We hypothesized that the clinical
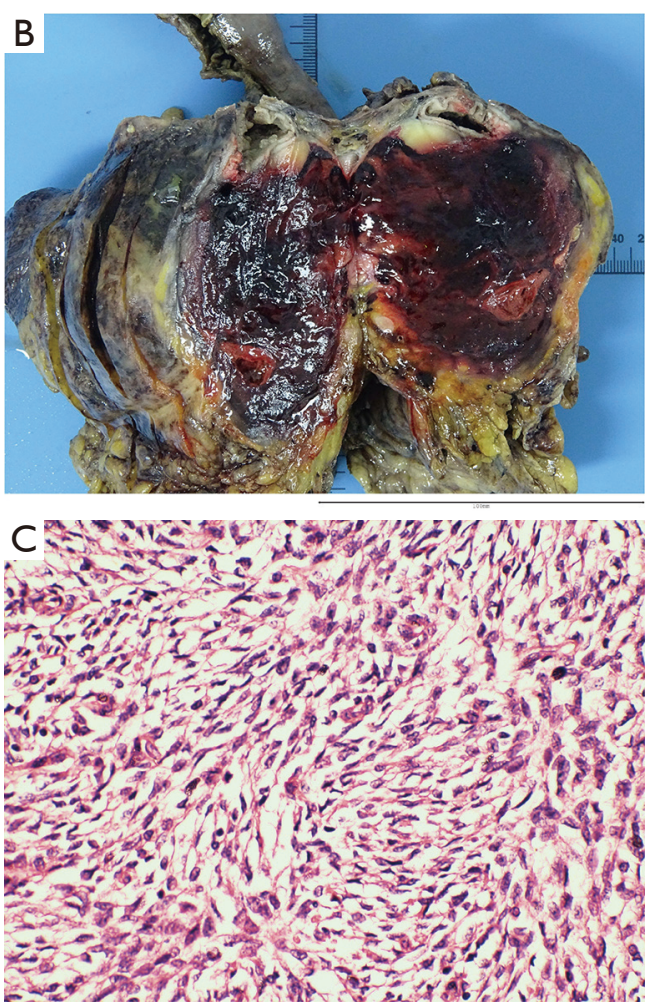

diagnosis could be pancreatic or colon cancer.

Ultimately, pancreaticoduodenectomy and right hemicolectomy were performed to resect the tumor completely (Panel B). The pathological examination confirmed the diagnosis as metastasis of DFSP to the pancreas (Panel C, staining method HE, magnification $40 \times 10)$. The tumor had invaded the duodenum and colon serosa, and was accompanied with extensive intratumoral bleeding. The patient recovered successfully and was discharged on the 13th day. 


\section{Acknowledgments}

Funding: None.

\section{Footnote}

Provenance and Peer Review: This article is a free submission to the Hepatobiliary Surgery and Nutrition. The article did not undergo external peer review.

Conflicts of Interest: Both authors have completed the ICMJE uniform disclosure form (available at http://dx.doi. org/10.21037/hbsn.2020.04.05). The authors have no conflicts of interest to declare.

Cite this article as: Jia B, Liu Y. A misdiagnosed abdominal tumor due to rare cause. HepatoBiliary Surg Nutr 2020;9(5):691692. doi: 10.21037/hbsn.2020.04.05
Ethical Statement: The authors are accountable for all aspects of the work in ensuring that questions related to the accuracy or integrity of any part of the work are appropriately investigated and resolved.

Open Access Statement: This is an Open Access article distributed in accordance with the Creative Commons Attribution-NonCommercial-NoDerivs 4.0 International License (CC BY-NC-ND 4.0), which permits the noncommercial replication and distribution of the article with the strict proviso that no changes or edits are made and the original work is properly cited (including links to both the formal publication through the relevant DOI and the license). See: https://creativecommons.org/licenses/by-nc-nd/4.0/. 